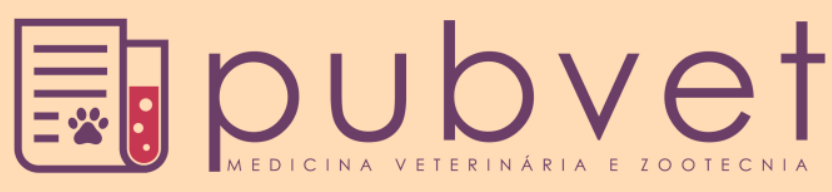

https://doi.org/10.22256/pubvet.v12n1a15.1-6

\title{
Lipoma subcutâneo gigante em região lombo-sacral de um cão: Relato de caso
}

Tatianne Alexandre Azevedo Viliotti ${ }^{*} \odot$, Hermógenes Josniel Rocha Macedo $^{1 \bullet}$, Maria Gabriela de Lima Chaves ${ }^{1} \bullet$, Raissa Correia Rodrigues de Oliveira ${ }^{1}$, Humberto Franco Silva $^{1}$, Richard Elaino de Oliveira Ferraz ${ }^{2} \bullet$

${ }^{I}$ Graduação em Medicina Veterinária pela Faculdade Terra Nordeste. Campus Caucaia. Caucaia-CE, Brasil.

${ }^{2}$ Médico Veterinário. Professor da Faculdade Terra Nordeste, setor de cirurgia de pequenos animais (Policlínica Veterinária Metropolitana). Campus Caucaia. Caucaia-CE, Brasil. E-mail: richard.ferraz@fatene.edu.br

*Autor para correspondência, E-mail: tatianneviliotti@gmail.com

RESUMO. O lipoma é considerado uma neoplasia mesenquimal comum benigna originada dos adipócitos ou de células gordurosas subcutâneas e ocasionalmente dérmicos. Podem ser caracterizados como massas únicas ou múltiplas de crescimento lento, sendo, nesta situação, a eleição de terapêutica cirúrgica por meio de excisão tumoral como alternativa viável sem a necessidade de associação com um tratamento quimioterápico. O objetivo deste estudo foi relatar o caso de uma cadela acometida por lipoma subcutâneo gigante em região lombo-sacral. Foi atendida na Policlínica Veterinária Metropolitana uma cadela, sem raça definida, pesando $16,70 \mathrm{~kg}$ e com 8 anos e 1 mês de idade. Durante a anamnese foi relatado aumento de volume abrangendo a região lombo-sacral do animal, de surgimento insidioso e que se desenvolvia lentamente com o passar dos meses. No exame clínico observou-se mucosas normocoradas, linfonodos normais, temperatura de $39,2^{\circ} \mathrm{C}$, presença de uma massa de grande tamanho, densa e de superfície macia e arredondada em região lombo-sacral. $\mathrm{O}$ resultado do hemograma e da bioquímica sérica não revelou alterações relevantes ao caso, apenas uma discreta anemia. $\mathrm{O}$ procedimento cirúrgico consistiu na execução de uma incisão elíptica ao redor da massa seguida de divulsão romba com toalhas de laparotomia até que fosse liberada toda a massa tumoral. O feixe ou pedículo fibroso que sustentava o tumor foi ligado e seccionado. A massa retirada possuía aspecto globoso, maciço e pendular medindo cerca de $16 \mathrm{~cm}$ no seu maior eixo e pesando cerca de $1,5 \mathrm{~kg}$. Ao corte, a massa se apresentava encapsulada, firme e com coloração amarelada, mimetizando tecido gorduroso. Coletou-se uma pequena amostra para exame histopatológico. O resultado revelou células gordurosas, agregados inflamatórios e células da derme. O procedimento cirúrgico por meio da excisão da massa se mostrou uma alternativa satisfatória para o tratamento único e definitivo desse tipo de tumoração.

Palavras chave: excisão tumoral, fêmea, idoso, neoplasia, tumor cutâneo

\section{Giant subcutaneous lipoma in the lumbosacral region of a dog: Case report}

ABSTRACT. Lipoma is considered a benign common mesenchymal neoplasm originating from adipocytes or subcutaneous and occasionally dermal fat cells. They can be 
characterized as single or multiple masses of slow growth, being, in this situation, the choice of surgical treatment by means of tumor excision as a viable alternative without the necessity of association with a chemotherapeutic treatment. The purpose of this study was to report the case of a giant subcutaneous lipoma in the lumbosacral region. A bitch, with no defined breed, weighing $16.70 \mathrm{~kg}$ and 8 years and 1 month old, was seen at the Metropolitan Veterinary Polyclinic. During the anamnesis, an increase in volume was reported covering the lumbosacral region of the animal, which appeared insidiously and developed slowly over the months. In the clinical examination, we observed normocorate mucosa, normal lymph nodes, temperature of $39.2^{\circ} \mathrm{C}$, presence of a mass of large size, dense and soft and rounded surface in the lumbosacral region. The hemogram and serum biochemistry results showed no relevant changes to the case, only mild anemia. The surgical procedure consisted of performing an elliptical incision around the mass followed by blunt divulsion with laparotomy towels until the entire tumor mass was released. The fibrous bundle or pedicle supporting the tumor was ligated and sectioned. The removed mass had a globular, massive, pendular aspect measuring about $16 \mathrm{~cm}$ on its long axis and weighing about $1.5 \mathrm{~kg}$. At cut, the mass was encapsulated, firm and with yellowish color, mimicking greasy tissue. A small sample was collected for histopathological examination. The result revealed fatty cells, inflammatory aggregates, and dermal cells. The surgical procedure through mass excision proved to be a satisfactory alternative for the single and definitive treatment of this type of tumor.

Keywords: tumor excision, female, elderly, neoplasia, cutaneous tumor

\section{Lipoma subcutáneo gigante en región lumbar-sacra de un perro: Reporte de un caso}

RESUMEN. El lipoma se considera una neoplasia mesénquima común benigna originada de los adipocitos o de las células grasas subcutánea y ocasionalmente dérmica. Pueden ser caracterizados como masas únicas o múltiples de crecimiento lento, siendo, en esta situación, la elección de terapéutica quirúrgica por medio de escisión tumoral como alternativa viable sin la necesidad de asociación con un tratamiento quimioterapéutico. El objetivo de este estudio fue relatar el caso de una perra afectada por lipoma subcutáneo gigante en región lombo-sacra. Fue atendida en la Policlínica Veterinaria Metropolitana una perra, sin raza definida, pesando $16,70 \mathrm{~kg}$ y con 8 años y 1 mes de edad. Durante la anamnesis se reportó un aumento de volumen que abarcaba la región lumbo-sacra del animal, de surgimiento insidioso y que se desarrollaba lentamente con el paso de los meses. En el examen clínico se observaron mucosas normocoradas, ganglios linfáticos normales, temperatura de $39,2^{\circ} \mathrm{C}$, presencia de una masa de gran tamaño, densa y de superficie blanda y redondeada en región lumbar-sacral. El resultado del hemograma y de la bioquímica sérica no reveló cambios relevantes en el caso, sólo una discreta anemia. El procedimiento quirúrgico consistió en la ejecución de una incisión elíptica alrededor de la masa seguida de divulsión romba con toallas de laparotomía hasta que se liberó toda la masa tumoral. El haz o el pedículo fibroso que sostenía el tumor fueron ligados y seccionado. La masa retirada poseía un aspecto globoso, macizo y pendular midiendo unos $16 \mathrm{~cm}$ en su mayor eje y pesando alrededor de $1,5 \mathrm{~kg}$. Al corte, la masa se presentaba encapsulada, firme y con coloración amarillenta, mimetizando tejido graso. Se tomó una pequeña muestra para el examen histopatológico. El resultado reveló las células grasas, los agregados inflamatorios y las células de la dermis. El procedimiento quirúrgico por medio de la escisión de la masa se mostró una alternativa satisfactoria para el tratamiento único y definitivo de ese tipo de tumoración.

Palabras clave: escisión tumoral, hembra, añoso, neoplasia, tumor cutáneo 


\section{Introdução}

Os tumores cutâneos são os neoplasmas mais frequentemente encontrados e diagnosticados nos animais domésticos (Meirelles et al., 2010). De acordo com Paranhos (2014), os quadros tumorais se apresentam, mais comumente, em cerca de $30 \%$ nos cães e com aproximadamente $70-80 \%$ de benignidade nessa espécie.

Em caráter epidemiológico percebe-se que os lipomas são afecções comuns em caninos e raros em felinos, sendo as cadelas castradas e idosas, aparentemente, as mais acometidas. Ademais, de acordo com Birchard \& Sherding (2008), a presença dessas tumores pode ter a obesidade como fator pré-disponente e a maioria dos animais que apresentam este quadro tem uma idade média de oito anos.

O conhecimento da anatomia da pele é importante para permitir a diferenciação entre tumores primários e metástases cutâneas (Daleck et al., 2008). A origem da maioria dos tumores cutâneos é desconhecida, entretanto alguns agentes externos e biológicos podem ter um papel importante no desenvolvimento destas neoplasias. Segundo Daleck et al. (2008) é a partir do comportamento biológico do tumor que pode-se classificar as neoplasias cutâneas em duas categorias, as de tumores primários que se originam no subcutâneo e na pele e os secundários compostos pelas metástases de pele.

O lipoma é considerado uma neoplasia mesenquimal comum benigna originada dos adipócitos ou de células gordurosas subcutâneas e ocasionalmente dérmicos (Silva et al., 2017). Podem ser caracterizados como massas únicas ou múltiplas de crescimento lento, sendo, nesta situação, a eleição de terapêutica cirúrgica por meio de excisão tumoral como alternativa viável sem a necessidade de associação com um tratamento quimioterápico (Silva et al., 2017).

O diagnóstico presuntivo de tal enfermidade é realizado por meio de inspeção e palpação da massa durante o exame físico do animal. No entanto, deve-se levar em consideração também e instituir diagnóstico diferencial dermatológico na presença de alterações cutâneas com múltiplas lesões. Para isso, é de grande relevância a solicitação de exames complementares, tais como: hematológicos, bioquímicos, exames de imagens e avaliações cito e histopatológicas. A partir disso, pode-se determinar o tipo celular neoplásico, a definição, o estadiamento do tumor e ainda, favorecer o planejamento cirúrgico (Silva et al., 2017).

Nos casos de neoplasia benigna o prognóstico pode se enquadrar em duas configurações. Favorável para os lipomas bem circunscritos e reservados para os tumores infiltrativos, visto que o percentual de recidivas é alto e há, ainda, possibilidade de gerar destruição dos tecidos adjacentes (Paranhos, 2014).

Diante da raridade em literatura deste quadro, o objetivo deste estudo foi relatar o caso de uma cadela acometida por lipoma subcutâneo gigante em região lombo-sacral.

\section{Relato de caso}

Uma cadela, sem raça definida, pesando 16,7 $\mathrm{kg}$ e com 8 anos e 1 mês de idade foi previamente atendida na Policlínica Veterinária Metropolitana (HVM), no município de Caucaia, Ceará, Brasil. Durante a anamnese foi relatado aumento de volume abrangendo a região lombo-sacral do animal, de surgimento insidioso e crescimento lentamente progressivo ao longo de meses, repercutindo em dificuldade de deambulação.

No exame clínico observaram-se mucosas normocoradas, linfonodos normais, temperatura de $39,2^{\circ} \mathrm{C}$, presença de uma massa de grande tamanho, densa e de superfície macia e arredondada em região lombo-sacral (Figura 1), exame neurológico, auscultação cardíaca e pulmonar dentro dos padrões normais para a espécie. $\mathrm{O}$ animal não apresentava ectoparasita e nenhuma outra alteração sistêmica. Solicitou-se perfil hematológico, ureia, creatina e dosagem sérica de ALT como exames complementares. Mediante histórico e quadro clínico apresentado, adotou-se execução de tratamento cirúrgico por meio de excisão tumoral.

\section{Resultados}

No resultado do hemograma não se observou alterações relevantes, senão uma discreta anemia (4,9 milhões $\left./ \mathrm{mm}^{3}\right)$. Não se observou alterações bioquímicas, com valores de creatina e dosagem sérica de ALT dentro das faixas de normalidade para a espécie.

No exame físico pré-operatório observou-se tempo de preenchimento capilar de 2 segundos, frequência cardíaca de $142 \mathrm{bpm}$, frequência respiratória de $25 \mathrm{mpm}$ e presença de massa na região lombo-sacral onde se efetuou tricotomia e assepsia prévia para cirurgia (Figura 2 A). 


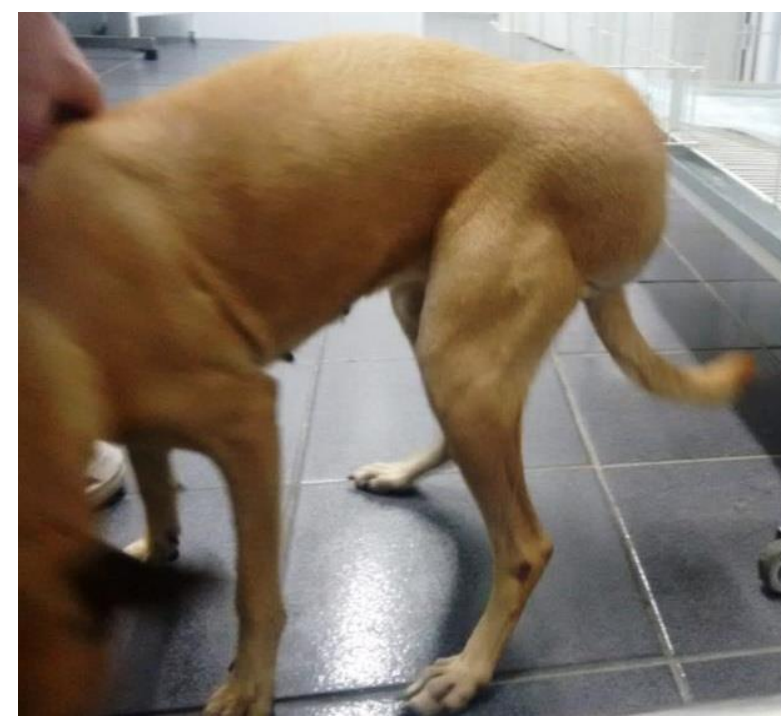

Figura 1. Canino, fêmea, 8 anos e 1 mês de idade, $16,7 \mathrm{~kg}$, sem raça definida. Fonte: arquivo pessoal.

No período pré-anestésico instituiu-se fluidoterapia com solução fisiológica $0,9 \%$ e medicação pré-anestésica incluindo acepromazina e cloridrato de tramadol em doses de $0,5 \mathrm{~mL}$ e 0,4 $\mathrm{mL}$, via intravenosa e intramuscular, respectivamente. A indução foi realizada através da administração de diazepam em dose de 1,6 mL e cetamina com $0,8 \mathrm{~mL}$, ambos por via intravenosa. Após induzida a anestesia, o paciente foi intubado, sendo a manutenção realizada com isofluorano.

O procedimento cirúrgico consistiu na execução de uma incisão elíptica ao redor da massa seguida de divulsão romba com toalhas de laparotomia até que fosse liberada toda a massa tumoral (Figura 2; $\underline{\mathrm{B}}, \underline{\mathrm{C}}$ e $\underline{\mathrm{D}}$ ). O feixe ou pedículo fibroso que sustentava o tumor foi ligado e seccionado. Em seguida, aproximou-se o espaço morto em padrão ziguezague com fio multifilamentoso poliglactina 910 e a pele foi suturada em padrão simples interrompido utilizando fio nylon 2-0.

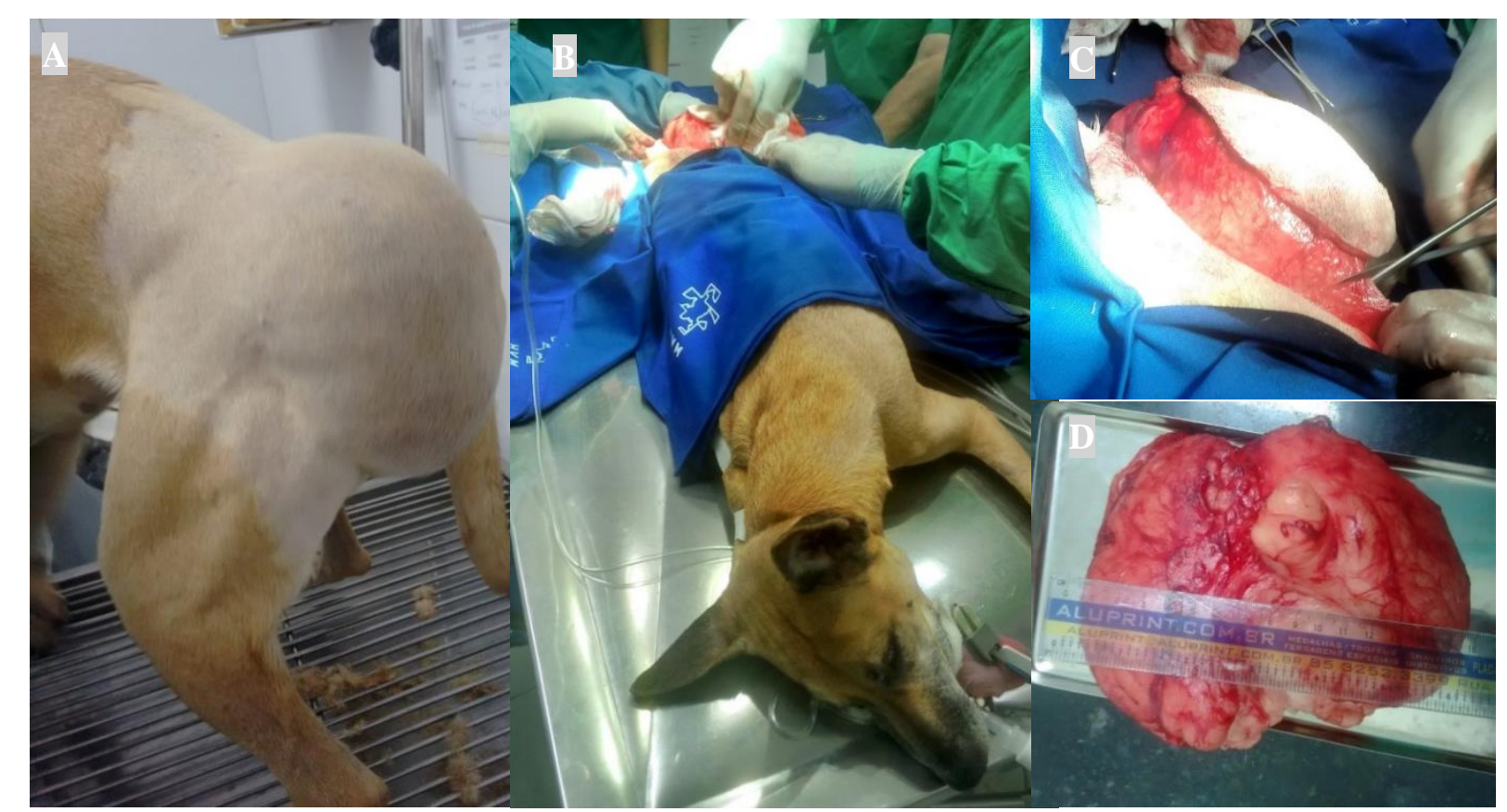

Figura 2. Exérese de massa tumoral em região lombo-sacral. A- Tricotomia e assepsia do campo cirúrgico. B- Incisão cutânea e subcutânea. C- Divulsão dos tecidos e exposição do tumor. D- Tumor em tamanho aproximado de $15 \mathrm{~cm}$. Fonte: arquivo pessoal.

A massa retirada possuía aspecto globoso, maciço e pendular medindo cerca de $16 \mathrm{~cm}$ no seu maior eixo e pesando cerca de $1,5 \mathrm{~kg}$. Ao corte, a massa se apresentava encapsulada, firme e com coloração amarelada, mimetizando tecido gorduroso. Coletou-se uma pequena amostra da massa tumoral para realização de exame histopatológico. O resultado revelou células gordurosas, agregados inflamatórios e células da derme.

Posteriormente, prescreveu-se como terapêutica pós-operatória a administração de cefalexina $30 \mathrm{mg} / \mathrm{kg}$ b.i.d. durante 7 dias como terapia antibacteriana e cetoprofeno 1 $\mathrm{mg} / \mathrm{kg}$ s.i.d. por 3 dias como tratamento antiinflamatório, ambos por via oral, após a 
alimentação. Ademais, indicou-se o uso de iodopovidona para higiene da ferida cirúrgica e medicação tópica para auxílio na cicatrização.O paciente retornou passados quinze dias do procedimento cirúrgico com evidente melhora do quadro clínico (Figura 3).

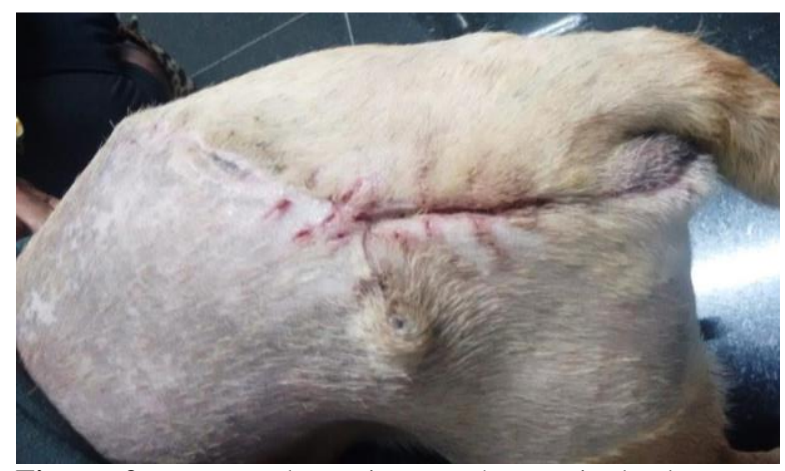

Figura 3. Retorno do paciente após a retirada da massa tumoral e dos pontos em região lombo-sacral. Fonte: arquivo pessoal.

\section{Discussão}

As informações de idade, sexo e crescimento tumoral mostradas no caso de lipoma deste estudo corroboram os achados de Gschwendtner (2015), quando afirmaram que a grande maioria dos lipomas possuem um crescimento lento e tal enfermidade geralmente acomete animais com uma idade média entre 7 e 8 anos. No sucessivo, Goldschmidt \& Shofer (1992) afirmaram em seus estudos que além da idade, as fêmeas eram consideradas os animais mais predispostos a tal afecção.

As características morfológicas encontradas no tumor da paciente se enquadravam nas mesmas descrições de lipoma proposta por Paranhos (2014), o qual relatava serem tumores bem circunscritos, encapsulados, massas macias, de colorações esbranquiçadas e amareladas indistinguíveis de tecido adiposos normais e móveis.

De acordo com Magalhães et al. (2001), o exame citopatológico propicia informações rápidas e que direcionam as condutas clinicas e cirúrgicas necessárias ao paciente. No entanto, nesse caso, a citologia revelou células gordurosas, agregados inflamatórios e células da derme, não sendo suficientemente conclusivo para confirmação do lipoma.

A confirmação do lipoma se deu pelo exame histopatológico realizado a partir de prévia amostra coletada durante a cirurgia. Souza et al.
(2010) afirmam que o exame histopatológico continua sendo o padrão ouro no diagnóstico de lipoma.

Apesar de o lipoma ser categorizado como baixo risco iminente a vida animal e de caráter benigno, os lipomas possuem um comportamento expansivo. O tamanho exagerado presente no animal causava incômodo e transtornos cotidianos ligados a atividades simples e ao seu bem-estar, devido justamente à localização anatômica e a compressão nervosa. Segundo Gschwendtner (2015), geralmente, a localização anatômica desses tumores pode causar problemas ao bem estar dos animais à medida que esta aumenta seu volume de forma exagerada, causando determinado tipo desconforto ou um quadro de dor quando se torna ulcerada. Dessa forma, a excisão cirúrgica foi a alternativa mais viável para melhora deste quadro.

\section{Conclusão}

Os lipomas são tumores encontrados em cães e são geralmente de natureza benigna. Todavia, o relato de um lipoma gigante juntamente à descrição da técnica de exérese é escasso em literatura. O procedimento cirúrgico por meio da excisão da massa se mostrou uma alternativa satisfatória para o tratamento único e definitivo desse tipo de tumor.

\section{Referências Bibliográficas}

Birchard, S. J. \& Sherding, R. G. 2008. Manual Saunders: clínica de pequenos animais, São Paulo.

Daleck, C. R., De Nardi, A. B., Rodigheri, S. M. \& Motta, F. R. 2008. Neoplasia do sistema urinário. Roca, São Paulo.

Goldschmidt, M. H. \& Shofer, F. S. 1992. Skin tumors of the dog and cat. Pergamon Press Ltd, Oxford.

Gschwendtner, G. 2015. Relatório de estágio e revisão bibliográfica relacionando lipoma e obesidade em cães.

Magalhães, A. M., Ramadinha, R. R., Barros, C. S. L. \& Peixoto, P. V. 2001. Estudo comparativo entre citopatologia e histopatologia no diagnóstico de neoplasias caninas. Pesquisa Veterinária Brasileira, 21, 23-32.

Meirelles, A. E. W. B., Oliveira, E. C., Rodrigues, B. Á., Costa, G. R., Sonne, L., Tesser, E. S. \& Driemeier, D. 2010. Prevalência de 
neoplasmas cutâneos em cães da Região Metropolitana de Porto Alegre, RS: 1.017 casos (2002-2007). Pesquisa Veterinaria Brasileira, 30, 968-973.

Paranhos, C. A. 2014. Neoplasias cutâneas caninas: um estudo descritivo de 4 anos. Medicina Veterinária. Universidade de Trásos-Montes e Alto Douro, Vila Real.

Silva, F. L., Silva, T. S., Sousa, F. B., Sousa Junior, F. L., Pereira, L. J. C., Cruz Silva, J. \& Bezerra, F. B. 2017. Lipoma subcutâneo abrangendo as regiões cervical e peri-auricular de um canino: Relato de caso. Pubvet: Publicações em Medicina Veterinária $e$ Zootecnia, 11, 363-370.
Souza, C. G., Souza, D. O., Nunes, T. d. S. \& Araújo, R. P. C. 2010. Tratamento de múltiplos lipomas de língua: Relato de caso clínico. Revista de Ciências Médicas e Biologicas, 9, 104-107.

Article History:

Received 19 September 2017

Accepted 9 October 2017

Available online 28 November 2017

License information: This is an open-access article distributed under the terms of the Creative Commons Attribution License 4.0, which permits unrestricted use, distribution, and reproduction in any medium, provided the original work is properly cited. 